\title{
ALGUNS ASPECTOS DA LUTA PELA EFETIVAÇÃO DO DIREITO À AUTODETERMINAÇÃO DO POVO INDÍGENA PAITER SURUÍ: A EDUCAÇÃO, A CULTURA E A TERRA. ${ }^{1}$
}

\author{
Alceu Zoia ${ }^{2}$ \\ orcid.org/0000-0002-0512-9511 \\ Matilde Mendes ${ }^{3}$ \\ orcid.org/0000-0002-42264923
}

\begin{abstract}
RESUMO: O presente artigo analisa aspectos do direito dos povos indígenas à autodeterminação, à educação específica e diferenciada relacionada à cultura e ao direito a terra, bem como suas lutas para efetivação desses direitos. Assim sendo, o intuito é de averiguar se o Estado Brasileiro tem respeitado o disposto na legislação indigenista. Para tanto, utilizou-se da pesquisa qualitativa sócio-histórica, sendo os sujeitos pesquisados do povo indígena Paiter Suruí. Com suporte em Brandão (2006) e em Geertz (2008) pela presença de aspectos etnográficos. Desse modo, buscou-se direcionar o cerne da pesquisa aos direitos à autodeterminação, à educação específica e diferenciada relacionada à cultura e o direito a terra. Dessas análises e discussões conclui-se que os povos indígenas vêm sofrendo violências em seus territórios, em sua cultura e a necessidade de uma educação escolar que possa dialogar com a cultura do povo voltada para a sustentabilidade ambiental.
\end{abstract}

PALAVRAS-CHAVE: Paiter Suruí, autodeterminação, educação, cultura, terra indígena.

\section{SOME ASPECTS OF THE FIGHT FOR THE EFFECTIVENESS OF THE RIGTH TO SELF-DETERMINATION OF THE PAITER SURUÍ INDIGENOUS PEOPLE: EDUCATION, CULTURE AND EARTH.}

ABSTRACT: This article analyzes aspects of the right of indigenous peoples to selfdetermination, specific and differentiated education related to culture and the right

\footnotetext{
${ }^{1}$ Este artigo apresenta dados parciais da pesquisa dissertação apresentada à Universidade Estadual de Mato Grosso (UNEMAT), intitulada Educação escolar indígena Paiter Suruí e suas relações com os etnoconhecimentos, sob a orientação do Professor Doutor Alceu Zoia.

${ }^{2}$ Doutor em Educação. Professor da Faculdade de Educação e Linguagem FAEL, Sinop/MT e do PPGEdu/ UNEMAT, Cáceres /MT. Grupo de pesquisa: Educação e Diversidade no Contexto da Amazônia Legal Mato-grossense. Endereço: Av. dos Ingás 1001, Centro, Sinop/MT. Tel.: (66) 99999-4112.

${ }^{3}$ Mestre em Educação (UNEMAT, 2017). Professora das Faculdades Integradas de Cacoal - UNESC. Cacoal, RO, Amazônia Legal do Brasil. adv.matilde@uol.com.br
} 
to land, as well as their struggles for the realization of these rights. Therefore, the intention is to ascertain whether the Brazilian State has respected the provisions of indigenous legislation. For this, qualitative socio-historical research was used, with the subjects being researched by the Paiter Suruí indigenous people. Supported by Brandão (2006) and Geertz (2008) due to the presence of ethnographic aspects. Thus, we sought to direct the core of the research to the rights to self-determination, to specific and differentiated education related to culture and the right to land. From these analyzes and discussions, it can be concluded that indigenous peoples have suffered violence in their territories, in their culture and the need for school education that can dialogue with the culture of the people focused on environmental sustainability.

KEYWORDS: Paiter Suruí, self-determination, education, culture, indigenous land.

\section{ALGUNOS ASPECTOS DE LA LUCHA POR LA EFICACIA DEL DERECHO A LA AUTO DETERMINACIÓN DEL PUEBO INDÍGENA PAITER SURUÍ: EDUCACIÓN, CULTURA Y TIERRA}

RESUMEN: Este artículo analiza aspectos del derecho de los pueblos indígenas a la autodeterminación, educación específica y diferenciada relacionada con la cultura y el derecho a la tierra, así como sus luchas por la realización de estos derechos. Siendo así, la intención es determinar si el Estado brasileño ha respetado las disposiciones de la legislación indígena. Bien como, se utilizó la investigación sociohistórica cualitativa, siendo los sujetos encuestados son los pueblos indígenas Paiter Suruí. Basado en Brandão (2006) y Geertz (2008) por la presencia de aspectos etnográficos. De ese modo, buscó dirigir el núcleo de la investigación a los derechos de autodeterminación, a una educación específica y diferenciada relacionada con la cultura y el derecho a la tierra. A partir de estos análisis y debates, se puede concluir que los pueblos indígenas han estado sufriendo violencia en sus territorios, en su cultura y la necesidad de una educación escolar que pueda dialogar con la cultura de las personas centradas en la sostenibilidad ambiental.

PALABRAS CLAVE: Paiter Suruí, autodeterminación, educación, cultura, tierras indígenas.

\section{Introdução}

O presente artigo analisa aspectos do direito dos povos indígenas à autodeterminação, à educação específica e diferenciada relacionada à cultura e ao direito a terra, bem como suas lutas para efetivação desses direitos. As- 
sim sendo, com o intuito de averiguar se o Estado Brasileiro tem respeitado o disposto na legislação indigenista.

Para melhor compreender esses direitos, fez-se necessário trazer alguns aspectos do modo de viver e estar no mundo de um povo indígena. Por conseguinte, evidente a diversidade cultural existente entre os povos ameríndios. Desse modo, para o campo mais específico da pesquisa, buscou-se eleger o povo Paiter Suruí, que mora na Terra Indígena Sete de Setembro, limites com o Estado de Rondônia e Mato Grosso, ambos na Amazônia Legal Brasileira.

Esta pesquisa de campo foi realizada no ano de (2016) por Matilde Mendes para dissertação de mestrado em Educação pela Universidade Estadual de Mato Grosso (UNEMAT), com o título: Educação escolar indígena Paiter Suruí e sua relação com os etnoconhecimentos, conclusão em (2017), sob a orientação do Professor Doutor Alceu Zoia. Desse modo, no presente artigo, foi aproveitado material que não foi utilizado na dissertação, bem como alguns recortes dessa, com as devidas citações.

Assim sendo, os aportes bibliográficos versaram sobre doutrinas e legislações do direito dos povos indígenas, pesquisas históricas dentre outros. Com sustentação metodológica qualitativa sócio-histórica, por se tratar de estudos que envolvem relações humanas atuais e históricas. Sendo que parte dessa pesquisa foi de observação participante, para tanto buscou suporte em Brandão (2006), por também, utilizar-se da pesquisa de observação de povos originários, há aspectos etnográficos, Geertz (2008).

Com o intuito de organizar o corpo do texto, dividiu-o em tópicos: 1) os direitos à autodeterminação; 2) direitos à educação específica e diferenciada relacionada à cultura e o 3) direito a terra.

Uma vez que, o estudo tem como foco contribuir com essa área do conhecimento que versa sobre os povos originários e trazer para o centro de discussões científicas temas que boa parte da sociedade tende a tornar-se invisível. Já que os povos indígenas são uma realidade e compõem a diversidade cultural deste país, e acima de qualquer conceito: são seres humanos e assim devem ser reconhecidos e efetivados seus direitos e garantias individuais e coletivas pelo Estado Brasileiro.

\section{O direito à autodeterminação}

Os povos indígenas tem o direito à autodeterminação, que é uns dos alicerces da Declaração das Nações Unidas sobre os Direitos dos Povos Indígenas. Assim sendo, podem determinar com liberdade a sua condição política, 
o desenvolvimento econômico, social e cultural em seus assuntos internos e locais (ONU, 2008).

Porquanto, cada povo ameríndio é igual aos outros povos, e ao mesmo tempo, tem o direito de ser diferente ativo dos outros povos e de respeitar e serem respeitados por esses nas suas igualdades e diferenças. De modo que, os povos originários não devem sofrer violências por ser quem são, uma vez que ninguém deve ser obrigado a ser o que não é. Nesse sentido, o Estado brasileiro promulgou a Convenção n. 169 da OIT $^{4}$ e reconheceu, de forma vinculativa, o direito dos povos indígenas à autodeterminação: "a assumir o controle de suas próprias instituições e formas de vida e seu desenvolvimento econômico, e manter e fortalecer suas identidades, línguas e religiões, dentro do âmbito dos Estados onde moram".

Logo, a OIT reconhece como direito o que já pertencia aos povos indígenas. Esses, por tantas gerações, desenvolveram a gestão de seus territórios, estabeleceram regras de convivência interna, têm suas mitologias, seus rituais de curas, conhecimento e o uso das ervas curativas, bem como, possuem forma de educação específica, diferenciada, alguns bilingues, multilíngues, possuem relação de pertencimento com o meio ambiente. Além de construir alianças políticas com outras nações, que são estratégias de luta e sobrevivência. Esses direitos originários ameríndios foram construídos bem antes de o primeiro homem europeu vir à América do Sul.

Dessa forma, com o propósito de compreender aspectos da realidade vivida de um povo indígena em busca da efetivação de direitos perante o Estado Brasileiro, a pesquisa contou com a participação de algumas pessoas da etnia Paiter Suruí. Segundo Zoia e Mendes (2017), apud Cardoso (2014), os Paiter Suruí moram na Terra Indígena Sete de Setembro, Paiterey Karah, área de 247.869 ha, que faz limite com os estados de Rondônia e Mato Grosso, ambos na Amazônia Legal Brasileira. Esse povo é formado, atualmente, por quatro clãs: G̃apg̃ir (marimbondo amarelo); G̃amep (marimbondo preto); Makor (Taquara); Kaban (mirindiba: frutinha vermelha) com organização em metades por grupos exogâmicos patrilineares. Esses falam a língua Paiter Suruí do tronco Tupi e da família linguística Mondé, conforme relatos dos mais antigos, os Paiter eram 5.000 pessoas antes de terem contato com povos não ameríndios.

Quando esse povo teve o seu primeiro contato com representantes do Estado brasileiro em 1969, somente restavam 250 Paiter Suruí. Isso se deu

\footnotetext{
${ }^{4}$ Convenção no 169 da OIT. Organização Internacional do Trabalho sobre Povos Indígenas e Tribais, de forma vinculativa, foi promulgada, na íntegra, pelo Decreto n. 5.051 de 19 de abril de 2004 e consolidada pelo Decreto n. 10.088, de 05 de novembro de 2019.
} 
pelo avanço das frentes de colonização, principalmente, nas décadas de 70 e 80. Além das mortes nas lutas pela terra, essas se intensificaram por contágio de doenças virais (gripes, sarampos, tuberculoses, dentre outras) trazidas pelo não indígena. Esse povo, como outros originários, não tinha resistência imunológica contra essas doenças, que evoluíam com rapidez e levou muitos indígenas à morte.

Dados da Paiter.Org (2020), informam que os Paiter Suruí são, aproximadamente, 1.700 pessoas, distribuídas em 27 aldeias na Terra Indígena Sete de Setembro. Esse povo vem se destacando pelo protagonismo em enfrentar dificuldades e buscar soluções sustentáveis para melhorar a qualidade de vida nas aldeias. Ademais, dão bastante importância à transmissão da cultura, da língua materna pelos mais velhos aos mais jovens. Assim como, mostram interesse em aprender a desenvolver técnicas e produções para melhor gestão do território e fazer uso de tecnologias, participando de capacitações nesse sentido.

Exemplo dessa busca pela autodeterminação por meio da troca de conhecimentos foi o I SOEITXAWE - Congresso Internacional de Pesquisa Científica na Amazônia CT que ocorreu no Centro Cultural da Metareilá Povo Indígena Paiter Suruí (2015). Desse encontro resultou na publicação de um livro com os artigos científicos apresentados no evento, o que fortalece os avanços científicos na Amazônia Legal Brasileira, onde vive grande diversidade de povos indígenas que reivindicam seus direitos à autodeterminação. Também, é constante movimentos dos povos indígenas para determinação e exigências do Estado brasileiro para que crie possibilidades de avanços ao protagonismo dos povos indígenas. No entanto, as raras efetivações de direitos dos povos ameríndios no Brasil só vêm se tornando possível após o advento da Constituição Federal de 1988.

Uma vez que, o artigo 231, caput traz: "São reconhecidos aos índios sua organização social, costumes, línguas, crenças e tradições, e os direitos originários sobre as terras que tradicionalmente ocupam, competindo à União demarcá-las, proteger e fazer respeitar todos os seus bens".

Fato esse, observado por Mendes, Barbosa e Zoia (2017, p. 447): "resultado de muitos movimentos em prol da causa indígena, foram reconhecidos aos indígenas sua organização social, costumes, línguas, crenças e tradições, bem como os direitos originários sobre as terras que tradicionalmente ocupam, dentre outros direitos". Não só o artigo supracitado, mas também, cabe destacar o artigo 232 da mesma Carta Magna, que reconhece a autonomia dos povos indígenas de forma individual ou coletiva para pleitear seus direitos 
diretamente sem tutela: “Os índios, suas comunidades e organizações são partes legítimas para ingressar em juízo em defesa de seus direitos e interesses, intervindo o Ministério Público em todos os atos do processo". Isso significa que os povos indígenas poderão ir aos tribunais pátrios reivindicar seus direitos sem serem assistidos pela Fundação Nacional do Índio, podendo demandar ações mesmo contra essa autarquia.

Assim como, o Decreto n. 7.747 de 05 de junho de 2012, que institui a Política Nacional de Gestão Territorial e Ambiental de Terras Indígenas, cujo artigo primeiro, em sua parte final, reafirma o princípio da autonomia ao tipificar que se deve respeitar a autonomia sociocultural, segundo o ordenamento jurídico vigente. Todavia, faz-se necessário um olhar para dentro dessas comunidades para se averiguar como esses instrumentos políticos estão sendo usados e se tem contemplado essas garantias de direitos.

\section{O direito à educação específica e diferenciada relacionada à cultura}

Em virtude de se buscar analisar como se dá à efetividade ou não da educação especifica e diferenciada na escola Tancredo Neves, fez-se necessário observar se há práticas pedagógicas na escola que contemplem a cultura originária. Visto que, o ordenamento jurídico brasileiro traz proteção nesse sentido.

De acordo com a Constituição Federal, artigo n. 215, parágrafo primeiro, atribui ao Estado o dever de prestar proteção às culturas populares, indígenas e afro-brasileiras, e de outros grupos que participam do processo civilizatório nacional.

Também, no caput do artigo 210 da Carta da República (BRASIL, 1988), consta: "Serão fixados conteúdos mínimos para o ensino fundamental, de maneira a assegurar formação básica comum e respeito aos valores culturais e artísticos, nacionais e regionais". E, no parágrafo segundo desse artigo assegura: "O ensino fundamental regular será ministrado em língua portuguesa, assegurada às comunidades indígenas também a utilização de suas línguas maternas e processos próprios de aprendizagem".

Pode-se observar, durante a pesquisa de campo, na Escola Indígena Estadual Tancredo Neves (2016), As práticas pedagógicas de uma professora e de um professor, que são da etnia Paiter Suruí. Esses lecionam às crianças do ensino fundamental primeiro seguimento e em suas práticas há o ensino escrito da Língua Materna, além da Língua Portuguesa, também foi possível observar o compromisso dos professores em transmitir as narrativas mitológicas da cultura Paiter aos alunos. 
Com relação aos alunos do ensino fundamental, segundo seguimento, foi possível observar durante uma aula ao ar livre com alunos do sexto e sétimos anos, mediada pelo professor indígena que ensina Língua Materna e Cultura do Povo e da professora, que não é de etnia indígena, da disciplina de Geografia. Essa aula aconteceu no meio de plantações agrícolas, embaixo de árvores onde os alunos observaram, comentaram e estudaram aspectos da agricultura sustentável, reflorestamento e narrativas mitológicas daquela comunidade indígena.

Isso ficou relatado por Mendes (2017, p. 65):

Ouvi uma narrativa mitológica durante uma aula, no meio da roça, embaixo de uma árvore, o professor olhou para um cupinzeiro próximo e perguntou se a turma sabia da história de antigamente daquele cupinzeiro, uns sabiam, outros confundiam as narrativas mitológicas e o professor fez a recontagem do mito, com calma, chamando a atenção para detalhes e dando ênfase à oralidade. Depois, a turma deveria reescrever a narrativa mitológica na Língua Materna e na Língua Portuguesa e criar desenhos para recontagem do mito em linguagem não verbal, essa foi uma atividade para fazer extraclasse.

Ainda durante a pesquisa de campo (2016) foi possível participar de uma roda de conversas semiestruturadas, no pátio da escola, com as cadeiras em círculo, professores e alunos do ensino médio da já mencionada escola, trabalharam o tema sustentabilidade na Terra Indígena Sete de Setembro, a pauta principal consistiu em: como retirar o sustento da terra e ao mesmo tempo manter a conservação ambiental. No decorrer dos diálogos, pode-se observar uma preocupação dos jovens com desmatamento florestal e indicaram e trouxeram sugestões de reflorestamento, indicando o projeto Pamine de Reflorestamento da Aldeia Lapetanha, também indicaram possibilidades de produção agrícola com sustentabilidade florestal.

Essa preocupação com o desmatamento foi observada por Mendes (2017, p. 50) nas respostas aos questionários aplicados com alunos do ensino médio da já mencionada escola indígena, os quais assim escreveram ao serem perguntados sobre o que sentem pelo lugar onde vivem:

Eu fico feliz porque ela dá as coisas que eu preciso e quando as pessoas desmatam eu fico triste (2016 - B).

Aqui na aldeia vejo a mata verde que me deixa feliz, mas o que me deixa triste é que desmata a mata e queima, mas também que eu vejo pessoas felizes, animais, e entre outras. O que eu 
não quero ver é a floresta desmatada e queimada (2016 - C).

(DISCENTES do ensino fundamental segundo seguimento e ensino médio, pesquisa realizada em 30 de junho de 2016). (p.50).

Isso demonstra que esses jovens têm uma relação de pertencimento com a terra onde vivem. Por certo, a preocupação com os avanços das devastações de áreas de florestas, para esses, não são somente árvores retiradas, mas parte da vida da comunidade, podendo colocar em risco, por exemplo, sobrevivência de povos com cultura de coletores e caçadores. Além de causar desequilíbrios que podem repercutir em danos ambientais de impacto imprevisível. Assim sendo, a preocupação em trazer para os espaços das aulas questionamentos sobre o meio ambiente sustentável provoca sentimentos e fazeres comprometido com a diversidade cultural, o reavivamento ou continuidades de práticas ancestrais benéficas à preservação da vida das e nas florestas, traz melhoria da qualidade de vida de todos nós.

Durante a pesquisa de campo, com a participação de em uma festa na escola indígena já mencionada, havia amostra de diversidade de comidas da cultura e pode-se observar que os Paiter Suruí têm uma alimentação própria da tradição e há incentivo aos alunos utilizem alimentos saudáveis. Neste sentido, esse povo mantém em suas roças tradicionais o cultivo de alimentos da época de antes do contato, mas também na comunidade se consome alimentos industrializados da cultura envolvente. Sendo assim, nos dizeres de Suruí (2015, p. 13):

Quando eu era recém-nascido me alimentava do leite da minha mãe, depois cresci e consumia os alimentos tradicionais, junto com o meu povo, que era cará cozido e assado, cará cozido com carne de caça e de pesca, bebia chicha doce de cará também, comia cará junto com peixe. Também me alimentava de batata-doce, milho torrado com carne, beiju de milho, frutas e mel de abelha, entre outros alimentos que era muito importante na alimentação tradicional do meu povo.

Todavia, ainda nos dizeres de Suruí (2015, p. 13):

Infelizmente, hoje consumo mais alimentos industrializados, comprados no mercado, como arroz, feijão, macarrão, óleo, farinha, suco, açúcar, carne, leite, biscoito, pão, refrigerante, café e outros alimentos enlatados. Consumindo também frutas como: laranja, maça, uva, pera, melancia e outras. 
A mudança repentina de hábitos alimentares segundo o mesmo autor trouxe doenças à comunidade provocadas pelo uso de produtos industrializados e pelo teor de agrotóxicos contidos nesses. Segundo o Decreto $\mathrm{n}$. 7747 (2012), deve-se dar prioridade ao resgate e valorização da alimentação da cultura tradicional. A disseminação de sementes, no Estado de Rondônia já ocorreu feiras de trocas de sementes entre povos indígenas com o intuito de se manter a alimentação saudável de outrora. Promovendo assim, a recuperação e conservação da agrobiodiversidade e dos demais recursos naturais essenciais à segurança alimentar e nutricional desses povos. A escola pode ser parceira nessas ações para a melhoria da qualidade de vida das pessoas daquela comunidade.

Ademais, os projetos na escola para ouvir a sabedoria dos mais veIhos $^{5}$, que passam pela oralidade os conhecimentos ancestrais aos mais jovens. Essa prática é muito comum entre os Paiter Suruí, mesmo com o deslumbramento pelo fetiche da cultura envolvente por alguns jovens. Pode-se observar que a cultura específica e diferenciada com força nos mitos, o uso da Língua Materna e o amor a terra onde vivem são alguns traços identitários desse povo.

Também, observa-se que a terra é sagrada nas narrativas mitológicas dos Paiter Suruí, e esses são, pela origem, intrinsicamente ligados à natureza:

Gerepti, Gerpati. São Garbaiwai, Donos-do-dia, senhores com força para fazerem acontecimentos no mundo. Garbaiwai, ainda hoje, são os que dominam ou controlam processos, dotados de poder. Os primeiros seres é que fizeram tudo. Já havia um pedaço de terra; Palop, Nosso Pai, fez muito mais, fez a terra toda. Foi perguntando a cada um dos outros o que iriam fazer. Uns ajudavam os outros, foram fazendo. Lakapoy fez as rochas, as montanhas, o mato. Palop fez seu irmão, Palop Leregu, fez também os homens (MINDLIN, 1996, p. 107).

Isso também se evidência com o mito do surgimento da mulher, contado à Mindlin por esse povo (1996, p. 100): “Antigamente, ainda não havia mulheres no mundo. Só havia um homem, chamado lapaeab, sozinho, Havia uma árvore rachada, que lapeab costumava namorar." Narra-se que "Tanto namorou, tanto namorou, que a árvore engravidou [...] Pouco depois, à noite a árvore explodiu e uma criança comecou a chorar." Dentro da mitologia desse povo, assim surgiram as mulheres. Portanto, uma árvore na cultura ancestral dos Paiter Suruí tem um sentido muito além do que é percebido pela cultura ocidental.

\footnotetext{
${ }^{5}$ A expressão "os mais velhos" é bastante recorrente entre os Paiter ao se referirem aos idosos, anciões da aldeia, por isso utiliza-se a expressão mais velhos, no sentido de sabedores, sábios.
} 
O processo educacional desse povo indígena, pelo que se pode observar, é contínuo e não está adstrito a uma aprendizagem descontextualizada da vida. Pode ser essa a fórmula desse e de outros povos de se ressignificar durante e após as invasões em seus territórios e buscar meios de resistir como nação, mesmo perante tantas atrocidades sofridas. Há uma educação estruturante interna que os fortalece para continuar em defesa de seus direitos originários.

\section{Direito a terra}

"Quando o yara entrou na aldeia, viu a casa que estava à sua frente, abriu com as mãos um buraco nas paredes de palha da casa para ver do outro lado e dar continuidade à demarcação da linha." G̃asalab Surui ${ }^{6}$

No âmbito do direito indígena internacional, destaca-se quanto às garantias da terra para os povos indígenas a Convenção n. 169 da OIT, em seu artigo 13 consta, que:

Ao aplicarem as disposições desta parte da Convenção, os governos deverão respeitar a importância especial que para as culturas e valores espirituais dos povos interessados possui a sua relação com as terras ou territórios, ou com ambos, segundo os casos, que eles ocupam ou utilizam de alguma maneira e, particularmente, os aspectos coletivos dessa relação.

Neste sentido, a Constituição Federal do Brasil, reconhece o direito originário dos povos indígenas sobre as terras ocupadas por esses. Sendo que o artigo 231, caput, traz: "São reconhecidos aos índios sua organização social, costumes, línguas, crenças e tradições, e os direitos originários sobre as terras que tradicionalmente ocupam, competindo à União demarcá-las, proteger e fazer respeitar todos os seus bens". Esses direitos se desenvolvem no decorrer dos parágrafos desse artigo.

Dentre esses, a posse permanente e o direito ao usufruto sobre as terras que tradicionalmente ocupam, abrangendo as que esses habitam em caráter permanente, além das "utilizadas para suas atividades produtivas, as imprescindíveis à preservação dos recursos ambientais necessários a seu bem-estar e as necessárias a sua reprodução física e cultural, segundo seus usos, costumes e tradições. Esses têm o direito de usufruir das riquezas do solo, dos rios e dos lagos existentes em suas terras. Além disso, a Constituição

${ }^{6}$ Ancião, os mais velhos, da etnia Paiter Suruí que viveu na época do contato com os não indígenas. 
protege a retirada ou utilização de recursos hídricos e riquezas minerais em terras indígenas, o que só pode ser possível com aprovação de lei específica pelo Congresso Nacional, após ouvir as comunidades indígenas que seriam afetadas, sendo que essas tem direito à participação dos resultados da lavra.

Assim sendo, a Convenção 169 da OIT assegura aos povos indígenas o direito de serem consultados de forma prévia, esclarecida e de boa fé e que o empreendimento não coloque em risco a vida dos presentes e futuras gerações daquele território. Ademais, tal como a Constituição Federal, impede a remoção forçada desses de seus territórios. É de salientar, que a Carta da República traz expresso que são nulos e extintos, não produzindo efeitos jurídicos, os atos que tenham por objeto a ocupação, o domínio e a posse das terras indígenas. Afirma que a União não pagará a terra nua aos invasores, apenas as benfeitorias derivadas da ocupação de boa-fé, na forma da lei. É de referir, a proteção às terras indígenas é um direito originário, já reconhecido pelo Alvará Régio de 1680, segundo $\operatorname{ANPR}^{7}$ (2018).

Insta ainda destacar que as terras indígenas, são inalienáveis e indisponíveis. Sendo os direitos sobre elas, imprescritíveis. Ao assim dispor, a Constituição declara as garantias para que os povos indígenas não sejam esbulhados de suas terras pelo pseudoavanço da expansão econômica, essa visa o enriquecimento de alguns grupos do agronegócio em prejuízo ao meio ambiente e a vida dos presentes e futuras gerações, sejam elas índias ou não.

Todavia, a efetivação e a manutenção desses direitos, ainda, é uma luta contínua para praticamente todos os povos indígenas no Brasil. Mesmo os que já se encontram com suas terras devidamente demarcadas, há sempre a preocupação com Projetos de Lei ou Medidas Provisórias com intenções de retirar os direitos dos povos indígenas garantidos pela Constituição Federal. Essa política de assédio por invasões às terras indígenas tem-se intensificado nos anos de 2019 e 2020, devido o próprio Estado Brasileiro, por meio do Presidente da República, ter discursos e projeto de lei com objetivo de incentivare permitir a exploração de minérios e do agronegócio dentro das terras indígenas.

Esse tipo de exploração já ocorreu com mais intensidade nas décadas de 70 e 80, e como já relatado, os Paiter Suruí, bem como muitos povos da Amazônia Legal Brasileira, quase foram dizimados, outros desapareceram.

Sendo assim, esse processo migratório desordenado avançou dentro das terras já habitadas por várias etnias indígenas na Amazônia Legal Brasileira. No entanto, com muita resistência por esses povos, não foram exterminados pelos invasores. Ferreira (2017), traz dados referente a povos indígenas no Es-

${ }^{7}$ Associação Nacional dos Procuradores da República. 
tado de Rondônia, segundo Ferreira esse em Rondônia há 43 Terras Indígenas, dentre essas 20 são homologadas, as restantes dependem de identificação e demarcação pelo Governo Federal. Essas terras são habitadas pelo menos por sessenta povos indígenas, dentre esses há quinze povos em condição de isolamento voluntário.

Ainda, conforme dados da CIMI/RO, (2015) e Sesai apud Ferreira (2017) há em torno de 15 mil indígenas que vivem no Estado de Rondônia. Isso indica que a não conclusão dos processos demarcatórios e homologação dessas terras traz grave risco à segurança dos povos indígenas que nelas habitam. Esses ficam à mercê de ataques de garimpeiros, madeireiros, caçadores, latifundiários e tantos outros invasores. Criando assim, insegurança a esses povos, principalmente, para reivindicar judicialmente o direito em continuar nas terras ainda não homologadas, e por outro lado, abre espaço para as regularizações de terras por invasores.

Dentro desse contexto de lutas as histórias se repetem, apesar de já fazer algumas décadas do ocorrido com os Paiter Suruí, que até a presente data, ainda sofrem invasões em seu território de moradia e subsistência. Esse recorte representa as vozes de muitos povos da Amazônia Legal Brasileira.

\begin{abstract}
Os colonos, através das Linhas, passaram a ocupar o território que posteriormente foi demarcado e homologado como terra indígena pelo governo federal. Após a demarcação, meu povo foi à frente com esses colonos, na luta, apenas com arco e flecha, para desocupação do nosso território. Na época, éramos apenas 250 pessoas. Segundo Almir Suruí, aproximadamente 80 homens Paiter Suruí foram enfrentar 1.000 famílias dos colonos. Pode-se imaginar que não era na base do diálogo, mas uma guerra civil, os Paiter Suruí com arcos e flechas, de um lado, e os colonos, do outro, com armas de fogo. Houve morte dos dois lados, dos Paiter Suruí e dos colonos. Então, a Força Nacional foi convocada pelo Governo Federal para vir e tentar minimizar os conflitos em torno das frentes de invasão da Terra Indígena. A Cruz Vermelha também veio ajudar as vítimas dessa guerra civil que se estabeleceu na região. O caso ganhou projeção nacional, devido à sua gravidade (SURUÍ, 2013, p. 26).
\end{abstract}

A epígrafe, que abre este capítulo, demonstra parte do genocídio ocorrido contra os povos indígenas na década de 70. "Quando o yara ${ }^{8}$ entrou na aldeia, viu a casa que estava à sua frente, abriu com as mãos um buraco nas paredes de palha da casa para ver do outro lado e dar continuidade à

${ }^{8}$ Homem branco. 
demarcação da linha". Consta das narrativas dos Paiter Suruí que as pessoas, que estavam dentro da oca invadida pelo servidor público, se encontravam doentes com sarampo e gripe.

Isso deixa claro pela fala de G̃asalab Suruí, o tratamento de invisibilidade para as pessoas humanas que estavam dentro da oca. Essa foi invadida pelo agrimensor, funcionário do Governo, fazia a tipografia para a abertura de estradas rurais, linhas, para demarcar os lotes para serem entregues aos colonos. Grandes áreas de terras, as mais férteis eram destinadas à latifundiários que as negociavam diretamente com integrantes do governo da ditadura militar. Cujo slogan de campanha do Governo de Ditadura Militar para atrair pessoas à Amazônia Legal Brasileira era: "terras sem homens, para homens sem-terra", passando a falsa ideia de que a região amazônica era um vazio demográfico.

Em outras palavras e apresentação de fatos acontecidos, as invasões não são histórias do passado, em tempos atuais estão bem presentes. Praticamente todas as terras indígenas da Amazônia vêm sofrendo com os processos de invasões, com destaque para a TI dos Uru-Eu-Wau-Wau, no Estado de Rondônia. Isso tem aumentado desde o começo do ano de 2019. "As falas contra os povos indígenas do novo governo estimulam as invasões", afirma Awapu Uru-Eu-Wau-Wau, liderança do povo Uru-Eu-Wau-Wau, em entrevista ao Instituto Socioambiental (ISA, 2019). Em 2020, Ari Uru-Eu-Wau-Wau foi encontrado morto, há suspeita de assassinato, esse tinha a função dentro da aldeia de registrar e denunciar a extração ilegal de madeira dentro da terra indígena, segundo noticiado pela Kaninde.Org (2020):

A Associação de Defesa Etnoambiental - Kanindé, junto com a Associação do Povo Indígena Uru-Eu-Wau-Wau - Jupaú, vimos através desta, com imenso pesar, informar o falecimento do indígena Ari Uru-Eu-Wau-Wau. Lamentamos profundamente a morte de Ari e denunciamos a falta de fiscalização e a dificuldade enfrentada pelo povo e pela Terra Indígena Uru-Eu-Wau-Wau. Ari era professor na aldeia 621, com 33 anos, e foi encontrado morto na manhã do dia 18 de abril de 2020, assassinado com aproximadamente quatro golpes na cabeça.

A Terra Indígena Uru-Eu-Wau-Wau vem sofrendo com pressões e invasões de grileiros, garimpeiros e madeireiros que ameaçam a vida dos indígenas. Tais fatos vinham sendo reiteradamente denunciados aos órgãos competentes, mas nenhuma providência foi tomada. 
Além dos assassinatos de pessoas de etnias indígenas, há outro fato grave, segundo Garnelo ${ }^{9}$, em entrevista concedida ao programa Ambiente É o Meio, da Rádio USP, afirmou que: "Existe uma ação política bastante visível e a razão é econômica, temos uma economia, infelizmente, predatória e que não tem nenhum respeito às questões ambientais no País". Ainda para Garnelo (2018) essas violências históricas da colonização, que consistem em invasões de terras, discriminação e desigualdades relativas aos modos de vida do mundo não indígena, dentre outros fatores sociais, podem favorecer a autoagressão indígena, e resultar em suicídios.

Mediante esses fatos, o CIMI (2017, p.139), divulgou relatório com preocupações por Violência por omissão do poder público, destacando o alto índice de suicídio entre pessoas de etnia indígena na Região Amazônica, soma-se 128 óbitos. O que demonstra que há algo de muito errado no cumprimento da aliança formada pelo Estado, por meio da Convenção no 169 da OIT, para assegurar a autodeterminação dos povos indígenas em seus territórios.

Ainda, conforme o narrador G̃aami Anine Suruí, ouvido por Pappiani e Lacerda (2016, p. 148 e 177), afirma que sobre o tempo presente: "Os antigos já diziam que um dia haveria muita destruição, que os brancos iam acabar com todo o povo Suruí para se apoderarem da terra. Eles sabiam. Os antigos sabiam que existia deus, que existia o homem branco, que a lei dele é muito terrível". Percebe-se nos dizeres do ancião G̃aami Anine Suruí preocupação com o ordenamento jurídico brasileiro com relação à proteção dos direitos dos povos indígenas, também pode-se observar na pesquisa de campo na fala de um jovem Paiter preocupação com as invasões e as retiradas ilegais de madeira desse território.

Segundo Mendes (2017, p. 49) ao entrevistar jovens da etnia Paiter Suruí sobre morar na Terra Indígena Sete de Setembro:

\begin{abstract}
"Meu sentimento por esse lugar onde vivo é muito bom para mim porque neste lugar tem muitas brincadeiras, tem mais o trabalho na roça e banho no rio". "Bom, neste lugar que eu moro é mais ou menos bonito e eu não gosto muito de viver neste lugar neste jeito porque nós somos índios e nós temos nossos direitos, depois do contato mudou tudo a nossa cultura no nosso jeito de ser índio e cada dia mais a nossa cultura está sumindo e é por isso que eu não gosto de viver desse jeito assim. A nossa terra indígena está se acabado e as nossas árvores estão sendo cortado e é por isso que eu não gosto muito desse lugar (DISCENTES do ensino fundamental segundo seguimento e ensino médio, pesquisa realizada em 30 de junho de 2016).
\end{abstract}

${ }^{9}$ Maria Luiza Garnelo Pereira, integrante do GT Saúde Indígena da Abrasco. 
Dessa forma, o direito a terra aos povos indígenas, assegurado pelo ordenamento jurídico brasileiro, ainda não é uma realidade, como quis a Assembleia Constituinte. Sendo assim, no artigo 57, dos atos transitórios, estipulou a partir da promulgação cinco anos à União para demarcar todas as terras indígenas no Brasil.

Portanto, o que se depreende de todo o exposto é que nem as terras indígenas já demarcadas estão tendo suas fronteiras respeitadas a contento. Fato esse que se agrava e muito com a não demarcação e homologação, principalmente, quando se trata de índios isolados. Diante disso, as invasões de garimpeiros, madeireiros, posseiros, biopiratas, caçadores dentre outros que atormentam a vida dentro das comunidades índias, além de levar dor e sofrimento com assassinatos de lideranças que resistem aos invasores, também levam a destruição da fauna e flora, bem como das nascentes de água. A todos esses males, soma-se a chegada de doenças contagiosas, dentre essas a Covid-19.

\section{Da metodologia e análises dos resultados}

\section{a) Aspectos metodológicos}

Os caminhos que levaram à pesquisa científica foram pesquisas de observações e coletas de informações e aplicação de questionários ocorridos no ano de 2016. Os sujeitos pesquisados foram: professores, alunos, coordenadora pedagógica e administradora das escolas indígenas. Essa pesquisa foi desenvolvida para dissertação de mestrado em educação pela Universidade Estadual de Mato Grosso com o título: Educação escolar indígena Paiter Suruí e sua relação com os etnoconhecimentos, conclusão em (2017), sob a orientação do Professor Doutor Alceu Zoia.

Naquela oportunidade, foram entrevistadas 24 pessoas, sendo três professores e três professoras. Duas professoras não são da etnia indígena. A Chefe do NEEl e uma Coordenadora Pedagógica. Os alunos que quiseram participar da pesquisa foram 13, também três mulheres que trabalham com artesanatos quiseram participar. Deixei de entrevistar pessoas idosas, uma vez que são muito assediadas por pesquisadores e utilizei os depoimentos que essas deram às pesquisadoras Pappiani e Lacerda (2016).

Sendo assim, as pesquisas bibliográficas versaram sobre doutrinas e legislações do direito dos povos indígenas, pesquisas históricas dentre outros. Nesse sentido, a sustentação metodológica é qualitativa sócio-histórica, por se 
tratar de estudos que envolvem relações humanas, com apoio nas ideias de Brandão (2006) por também utilizar-se da pesquisa de observação participante. Também, podem-se considerar aspectos etnográficos, Geertz (2008, p. 212):

Da mesma forma que nos exercícios familiares de leitura atenta, pode-se começar em qualquer lugar, num repertório de formas de uma cultura, e terminar em qualquer outro lugar. Pode-se permanecer, como eu, numa única forma mais ou menos limitada, e circular em torno dela de maneira mais estável. Pode-se movimentar por entre as formas em busca de unidades maiores ou contrastes informativos. Pode-se até comparar formas de diferentes culturas a fim de definir-lhes o caráter para um auxílio mútuo. Entretanto, qualquer que seja o nível em que se atua, e por mais intrincado que seja o princípio orientador é o mesmo: as sociedades, como as vidas, contêm suas próprias interpretações. É preciso apenas descobrir o acesso a elas.

Não se utilizou, no presente estudo todo o material colhido na pesquisa de campo, por se tratar de abordagens sobre pontos não explorados na dissertação do mestrado e outros foram retirados alguns recortes daquela, com as devidas citações. Para melhor desenvolvimento da pesquisa, foram divididos em: Direito à autodeterminação, Direito à educação específica, diferenciada e relacionada com a cultura e direito a terra.

\section{b) Análise dos resultados}

De todo o exposto, verificou-se que os Paiter Suruí exercem certo protagonismo na gestão de seu território, quanto à escolha de lideranças representativas da comunidade, bem como o modo de trabalhar a terra. Com relação à educação foi possível perceber que há esforço dos professores indígenas e não indígenas em estabelecer diálogos com o conteúdo escolar e a cultura do povo.

Também, evidencia aspectos da autodeterminação as decisões dos assuntos pertinentes àquele povo são decididas por meio de reuniões com a presença de toda a comunidade da aldeia, e por vezes, quando o assunto é inerente a toda terra indígena, fazem-se reuniões por agrupamentos de aldeias ou com as lideranças. Cita-se, como exemplo, a reunião para decidir sobre como trabalhar o Programa Novo Mais Educação, criado pelo MEC, Portaria n. 1.144 de 2016. As reuniões foram realizadas por escolas indígenas e com base 
nas linhas do programa a comunidade escolheu e fez adequações para o que se decidiu ser mais benefício ao ensino-aprendizagem dos alunos e a essa. Escolheu, também, os monitores para trabalhar com o ensino de artesanatos aos alunos, bem como com os que iriam monitorar as oficinas de reflorestamento. Naquele momento, foi possível perceber, que mesmo com algumas linhas já estabelecida dentro do programa do governo federal, os sujeitos de direito, buscaram se adequar e escolher pensando no bem comum coletivo.

Dentre as legislações analisadas a Convenção n. 169 OIT, a Constituição Federal e o Decreto n. 7.747, 2012 trazem sustentação aos direitos dos povos indígenas. A Constituição, como já se discorreu, em capítulo destinado aos Índios, artigos n. 231 e 232 indica a segurança jurídica aos direitos básicos dos povos indígenas, no entanto, é preciso colocá-los em prática para que surtam seus efeitos legais.

A aplicabilidade desses direitos ainda é bastante insipiente e quando acontece sua aplicação, se dá após intensa luta dos movimentos indígenas, muitas vezes, ocasionando a morte de lideranças, principalmente, quando se trata da luta pela terra.

Já o Decreto destinado à implantação das Políticas Públicas de Gestão Territorial e Ambiental de Terras Indígenas (PNAGATI), também, deixa muito a desejar na implantação dessas políticas, uma vez que faltam subsídios do Governo Federal para a gestão de projetos que a torne eficaz. Pelo contrário, percebe-se uma ausência de interesse na demarcação das terras indígenas e a proteção dessas pelo Governo Federal, também, encontra-se bastante prejudicada a segurança, principalmente na Amazônia Legal Brasileira onde se intensifica a exploração ilegal de madeira e garimpo. Neste sentido, a OEA, por meio do CIDFH-Comissão Interamericana de Direitos Humanos, por meio da Resolução 35/2020 de 17 de julho de 2020, outorgou a favor dos povos indígenas Yanomami e Ye'kwana, que vivem na Amazônia Legal Brasileira, algumas comunidades índias em isolamento voluntário, por considerar que esses povos estão em situação grave e urgente, sendo que seus direitos correm risco de danos irreparáveis, uma vez que há invasão de milhares de garimpeiros nessas terras indígenas provocando destruição e levando doenças às comunidades, dentre elas a Covid-19 que já acometeu vários indígenas, na contramão, o governo brasileiro não estaria prestando a segurança necessária àquele povo. A medida requer, também, do Governo Federal medidas urgentes para a retirada dos garimpeiros da área e a assistência à saúde dos Yanomami e Ye'kwana.

Pelo que se avalia, a situação de violência e assédio estão atingindo todos os povos indígenas para alguns com maior intensidade. Apesar de so- 
frerem com essas invasões, os Paiter Suruí têm resistido e buscado, quase por conta própria, criar possibilidades de produção econômica sustentável, para alimento desse povo que tem aumentado sendo a terra já pouca ao sustento de todos, segundo a forma de antes do contato.

Mas, para que esse projeto de sustentabilidade dos povos indígenas possa ser desenvolvido é preciso que se tenha a segurança sobre esses territórios. Reitera-se com a devida demarcação e homologação das terras em que vivem e as que esses têm como base de sustentação econômica, cultural, religiosa e para a reprodução de seu povo. Destaca-se do artigo 4으, eixo 5 (BRASIL, Dec. 7.747 - PNGATI, 2012): "uso sustentável de recursos naturais e iniciativas produtivas indígenas:" são a garantia de usufruto das riquezas do solo, dos rios e dos lagos existentes em terras indígenas, com o propósito de fortalecer e promover as iniciativas produtivas indígenas, sendo que para tanto, além das terras, é necessário à disponibilização de novas tecnologias sustentáveis.

Outros objetivos importantes, que traz na alínea do citado eixo que é: a promoção e apoio a conservação e o uso sustentável dos recursos naturais utilizados na cultura indígena, com destaque ao artesanato indígena para fins comerciais. Essa prática de confecção de artesanato indígena pode ser constatada como uma das práticas da cultura Paíter Suruí, principalmente pelas mulheres que tecem redes tradicionais com algodão plantados nas roças da aldeia, fazem colares, anéis, pulseiras, brincos e outros enfeites utilizando recursos da natureza, também são exímios trabalhadores com cerâmica. Essas práticas, também, são passadas nas oficinas aos alunos na aula de cultura do povo e projetos. Essas produções são para consumo e o excedente é vendido para ajudar na subsistência da família. No entanto se percebe que faltam incentivos públicos para se efetuar as vendas desses produtos.

Também merece destaque a política do Estado Brasileiro apoiar a substituição de atividades produtivas não sustentáveis em terras indígenas por atividades sustentáveis, bem como apoiar estudos de impacto socioambiental de atividades econômicas e produtivas não tradicionais de iniciativa das comunidades indígenas. Neste ponto, deve-se trazer aqui, que os Paiter Suruí tem desenvolvido o melhor café orgânico da região, sendo contemplado com selo de qualidade, o que foi possível, também, por assistência técnica continuada. Destaca-se que junto às lavouras, na Aldeia Lapetanha, estão intercalando o plantio de árvores da região.

Esse reflorestamento alternado pode-se obervar e ouvir os alunos entusiasmados com as mudas de árvores em crescimento, algumas com placas para identificar o tipo de planta. Dessa forma, a educação escolar relacionada 
com a cultura específica e diferenciada de cada povo, poderá contribuir com a saúde alimentar, saúde de nossas florestas, de nossas águas e promover condições econômico-sociais isonômicas entre povos originários e não. Bem como a contribuição para todo o ecossistema com a manutenção da biodiversidade pela utilização sustentável da terra.

Também faz parte dessa afirmação à governança própria interna e a segurança jurídica da posse/propriedade da terra por esses sujeitos de direitos. Políticas públicas, gestadas com a participação efetiva das comunidades envolvidas, a partir de modelos sustentáveis de etnodesenvolvimento, podem ser caminhos para a afirmação coletiva dos povos indígenas e se fazerem respeitados perante o Estado Brasileiro.

No entanto, apesar de intensos movimentos dos povos indígenas em busca da autodeterminação de direitos, percebe-se que a concretude desses direitos está distante. As Conferências dos Povos Indígenas para fazer com que os Governos cumpram com o disposto na Convenção no 169 da OIT e na Declaração das Nações Unidas Sobre os Direitos dos Povos Indígenas vêm produzindo aos poucos intenções dos Governos internalizarem esses postulados humanitários. No entanto, o Brasil se mostra na contramão desses avanços com declarações pouco favoráveis à promoção da dignidade dos povos indígenas que por aqui residem.

\section{Considerações finais}

Cada povo indígena possui diferença no modo de viver e estar no mundo com conhecimentos específicos e diferenciados e isso os tornam únicos, mas ao mesmo tempo com plenos direitos de acesso a outros conhecimentos.

Para tanto, é necessário compromisso dos três Poderes, Executivo, Legislativo e Judiciário com a segurança dos Povos Indígenas e o respeito aos direitos originários sobre seus territórios, sua cultura, sua língua materna, religiosidade, regras e convivência.

Esses Poderes necessitam romper o comodismo ou favoritismo e enfrentar as questões indígenas a partir dos anseios dos próprios indígenas. Sendo assim, toda ação do Governo Brasileiro na esfera legislativa ou administrativa que envolva o modo de viver dos povos indígenas e seus territórios, por força de lei, precisa ocorrer à consulta prévia, informada, de boa-fé com o povo interessado.

Logo, não há mais espaço para a invisibilidade dos povos indígenas, esses existem e estão se organizando em movimentos em busca de seus 
direitos, na última década há uma presença mais constante desses povos indígenas em reivindicações. E isso os têm tornado fortes. Essa força coletiva fez com que o Governo atual recuasse ao querer diminuir direitos dos povos indígenas à saúde, não que esses direitos já conquistados deem a esses povos prestação de assistência à saúde com qualidade. Principalmente, para se enfrentar a pandemia de Covid-19 que tem acometido algumas pessoas das comunidades indígenas, e não se vê uma gestão pública eficaz neste sentido. Bem como no combate às invasões às terras indígenas, o que por sua vez reflete de forma negativa à educação, à cultura e à permanência na terra. Isso retira a autonomia dos povos ameríndios na gestão de seus territórios, e assim, mitiga o direito à autodeterminação dos povos indígenas.

\section{Referências}

ABRASCO. Entrevista com Luiza Garnelo sobre suicídio indígena para a Rádio USP. Disponível em: https://www.abrasco.org.br/site/outras-noticias/saude-da-populacao/entrevista-com-pesquisadora-luiza-garnelo-sobre-suicidio-indigena-para-radio-usp/33288/. Acesso aos 05 mai. 2019.

AMARAL, José Januário. Rondônia: colonização de novas terras Rondônia: colonização de novas terras . revista de educação, cultura e meio ambiente. http://www.revistapresenca.unir.br/artigos_presenca/11josejanuario_rondoniacolonizacaodenovasterras.pdf,. Acesso em 30 de abril 2019.

ANPR - Associação Nacional dos Procuradores da República.

Índios, Direitos Originários e Territorialidade. Organizadores: Gustavo Kenner Alcântara, Lívia Nascimento Tinôco, Luciano Mariz Maia. Brasília: ANPR, 2018

BRANDÃO, Carlos Rodrigues, (organização). Pesquisa Participante. São Paulo: Brasiliense, 2006.

BRASIL. Constituição da República Federativa do Brasil de 1988. Disponível em: http://www.planalto.gov.br/ccivil_03/constituicao/constituicao.htm. Acesso aos: 08 mai 2019.

BRASIL. MEC. Cadernos do Novo Mais Educação. Disponível em: <http://portal.mec.gov.br/docman/agosto-2017-pdf/70831-pnme-caderno-de-orientacoes-pedagogicas-pdf/file>. Acesso aos 20 jul de 2020.

BRASIL. Decreto no 7.747, de 5 de junho de 2012 - Institui a Política Nacional 
de Gestão Territorial e Ambiental de Terras Indígenas - PNGATI. Disponível em: http://www.planalto.gov.br/ccivil_03/_ato2011-2014/2012/decreto/ d7747.htm>. Acesso aos 20 de jul 2020.

CIMI. Violência contra os povos indígenas do brasil dados 2017. Disponível em: https://cimi.org.br/wp-content/uploads/2018/09/Relatorio-violencia-contra-povos-indigenas_2017-Cimi.pdf. Acesso aos 05 de mai. 2019.

FERREIRA, Iremar Antonio. Povos indígenas de Rondônia: rumo aos 518 anos de resistência. https://www.alainet.org/pt/articulo/189961, acesso aos 02 abr 2019.

GEERTZ, Cliff ord. A interpretação das culturas. Rio de Janeiro: LTC, 2008.

ISA. Índios isolados e de recente contato relatam ameaças de morte e invasão de territórios. Disponível em: https://www.socioambiental.org/pt-br/tags/indios-isolados. Acesso aos 05 de mai 2019.

GEERTZ, Cliff.Centenas de invasores entram na Terra Indígena Uru-Eu-Wau-Wau e preparam derrubada da floresta. Disponível em: .https://www. socioambiental.org/pt-br/blog/blog-do-monitoramento/centenas-de-invasores-entram-na-terra-indigena-uru-eu-wau-wau-e-preparam-derrubada-da-floresta. Acesso aos 05 mai 2019.

MENDES, Matilde Educação escolar indígena Paiter Suruí e sua relação com os etnoconhecimentos./Matilde Mendes. Cáceres/MT: UNEMAT, 2017. $142 f$.

MINDLIN, Betty. Vozes da origem. São Paulo: Ática, 1996.

MINDLIN, Betty. Mitos Indígenas. Seleção e organização Betty Mindlin e narradores indígenas. São Paulo: Ática, 2006.

OEA. CIDH. Emite medidas cautelares em favor dos membros dos povos indígenasYanomami,Ye'kwana.Disponível:<http://www.oas.org/pt/cidh/prensa/ notas/2020/168.asp>.Acesso aos 20 jul 2020.

O.N.U. Declaração das Nações Unidas sobre os direitos dos povos indígenas - 2007. Disponível em: <http://www.direitoshumanos.usp.br/index.php/Direito-dos-Povos-Ind\%C3\%ADgenas/declaracao-das-nacoes-unidas-sobre-os-direitos-dos-povos-indigenas.html>. Acesso em 02 mai 2019.

O.N.U. Declaração Universal de Direitos Humanos. Disponível em: < http:// www.dudh.org.br/>.Acesso em 02 mai 2019.

O.N.U. OIT. Convenção nº 169 da Organização Internacional do Trabalho - OIT 
sobre Povos Indígenas e Tribais. Disponível em:< http://www.planalto.gov. br/ccivil_03/_ato2004-2006/2004/decreto/d5051.htm>. Acesso em 02 mai 2019.

PAITER.ORG. Paiter Surui. Disponível em: <http://www.paiter.org/noticias/>. Acesso aos 16 jul 2020.

PREFEITURA DE CACOAL. Café dos Suruí e dos Tupari de Rondônia terá marca nacional da maior empresa do Brasil https://www.cacoal.ro.gov.

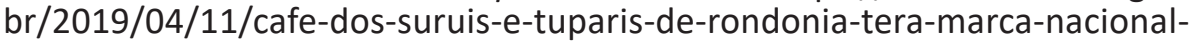
-da-maior-empresa-do-pais/

PAPPIANI, Angela e LACERDA, Inimá (organização). Histórias do começo e do fim do mundo - O contato do povo Paiter Suruí. São Paulo: Ikorẽ, 1a edição, 2016.

SOUZA FILHO, Carlos Frederico Marés de. O Renascer dos Povos Indígenas para o Direito. Curitiba: Juruá, 1999.

SURUÍ, Renato Labiway. A importância da alimentação tradicional na cultura do povo Paiter da Aldeia Lapetanha, Cacoal, Rondônia. Ji-Paraná, 2015. Disponível em: < http://www.deinter.unir.br/uploads/87443803/tcc/2015 Renato Labiway Surui.pdf>. Acesso aos 19 de jul de 2020.

KANIDE. ORG.Associação de defesa socioambiental. Nota de pesar e pedido por medidas urgentes. Disponível em: <http://www.kaninde.org.br/nota-de-pesar-de-ari-uru-eu-wau-wau/>. Acesso aos 19 jul 2020.

WANDERLEY, Claudia Marinho. I SOEITXAWE : Congresso Internacional de Pesquisa Científica na Amazônia / Claudia Wanderley. - $1^{\circ}$ edição.

- Campinas : Claudia Marinho Wanderley, Káchia Téchio...[et al], 2017.

ZOIA, Alceu. MENDES, Matilde. Protagonismo PaiterSuruí: práticas político-pedagógicas e suas relações com os etnoconhecimentos. Disponível em: $<$ http://periodicoscientificos.ufmt.br/ojs/index.php/educacaopublica/article/download/5002/3374>. Acesso aos 16 de jul de 2020.

Data de recebimento: 13.10 .2019

Data de aceite: 01.06.2020 